City University of New York (CUNY)

CUNY Academic Works

\title{
The Contribution of Advective Fluxes to Net Ecosystem Exchange in a High-Elevation, Subalpine Forest
}

\author{
Chuixiang Yi \\ CUNY Queens College \\ Dean E. Anderson \\ US Geological Survey \\ Andrew A. Turnipseed \\ National Center for Atmospheric Research \\ Sean P. Burns \\ University of Colorado Boulder \\ Jed P. Sparks \\ Cornell University
}

See next page for additional authors

\section{How does access to this work benefit you? Let us know!}

More information about this work at: https://academicworks.cuny.edu/qc_pubs/262

Discover additional works at: https://academicworks.cuny.edu

This work is made publicly available by the City University of New York (CUNY).

Contact: AcademicWorks@cuny.edu 
Authors

Chuixiang Yi, Dean E. Anderson, Andrew A. Turnipseed, Sean P. Burns, Jed P. Sparks, David I. Stannard, and Russell K. Monson

This article is available at CUNY Academic Works: https://academicworks.cuny.edu/qc_pubs/262 


\title{
THE CONTRIBUTION OF ADVECTIVE FLUXES TO NET ECOSYSTEM EXCHANGE IN A HIGH-ELEVATION, SUBALPINE FOREST
}

\author{
Chuixiang Yi,${ }^{1}$ Dean E. Anderson, ${ }^{2}$ Andrew A. Turnipseed, ${ }^{3}$ Sean P. Burns,${ }^{1,3}$ Jed P. Sparks, ${ }^{4}$ \\ David I. Stannard, ${ }^{2}$ and Russell K. Monson ${ }^{1,5,6}$ \\ ${ }^{1}$ Department of Ecology and Evolutionary Biology, University of Colorado, Boulder, Colorado 80309-0334 USA \\ ${ }^{2}$ U.S. Geological Survey, Water Resources Discipline, Denver Federal Center, Lakewood, Colorado 80225 USA \\ ${ }^{3}$ National Center for Atmospheric Research, Boulder, Colorado 80305 USA \\ ${ }^{4}$ Department of Ecology and Evolutionary Biology, Cornell University, Ithaca, New York 14853 USA \\ ${ }^{5}$ Cooperative Institute for Research in Environmental Sciences, University of Colorado, Boulder, Colorado 80309-0334 USA
}

\begin{abstract}
The eddy covariance technique, which is used in the determination of net ecosystem $\mathrm{CO}_{2}$ exchange (NEE), is subject to significant errors when advection that carries $\mathrm{CO}_{2}$ in the mean flow is ignored. We measured horizontal and vertical advective $\mathrm{CO}_{2}$ fluxes at the Niwot Ridge AmeriFlux site (Colorado, USA) using a measurement approach consisting of multiple towers. We observed relatively high rates of both horizontal $\left(F_{\text {hadv }}\right)$ and vertical $\left(F_{\text {vadv }}\right)$ advective fluxes at low surface friction velocities $\left(u_{*}\right)$ which were associated with downslope katabatic flows. We observed that $F_{\text {hadv }}$ was confined to a relatively thin layer (0-6 $\mathrm{m}$ thick) of subcanopy air that flowed beneath the eddy covariance sensors principally at night, carrying with it respired $\mathrm{CO}_{2}$ from the soil and lower parts of the canopy. The observed $F_{\text {vadv }}$ came from above the canopy and was presumably due to the convergence of drainage flows at the tower site. The magnitudes of both $F_{\text {hadv }}$ and $F_{\text {vadv }}$ were similar, of opposite sign, and increased with decreasing $u_{*}$, meaning that they most affected estimates of the total $\mathrm{CO}_{2}$ flux on calm nights with low wind speeds. The mathematical sign, temporal variation and dependence on $u_{*}$ of both $F_{\text {hadv }}$ and $F_{\text {vadv }}$ were determined by the unique terrain of the Niwot Ridge site. Therefore, the patterns we observed may not be broadly applicable to other sites. We evaluated the influence of advection on the cumulative annual and monthly estimates of the total $\mathrm{CO}_{2}$ flux $\left(F_{c}\right)$, which is often used as an estimate of NEE, over six years using the dependence of $F_{\text {hadv }}$ and $F_{\text {vadv }}$ on $u_{*}$. When the sum of $F_{\text {hadv }}$ and $F_{\text {vadv }}$ was used to correct monthly $F_{c}$, we observed values that were different from the monthly $F_{c}$ calculated using the traditional $u_{*}$-filter correction by -16 to $20 \mathrm{~g} \mathrm{C} \cdot \mathrm{m}^{-2} \cdot \mathrm{mo}^{-1}$; the mean percentage difference in monthly $F_{c}$ for these two methods over the six-year period was $10 \%$. When the sum of $F_{\text {hadv }}$ and $F_{\text {vadv }}$ was used to correct annual $F_{c}$, we observed a $65 \%$ difference compared to the traditional $u_{*}$-filter approach. Thus, the errors to the local $\mathrm{CO}_{2}$ budget, when $F_{\text {hadv }}$ and $F_{\text {vadv }}$ are ignored, can become large when compounded in cumulative fashion over long time intervals. We conclude that the "micrometeorological" (using observations of $F_{\text {hadv }}$ and $F_{\text {vadv }}$ ) and "biological" (using the $u_{*}$ filter and temperature vs. $F_{c}$ relationship) corrections differ on the basis of fundamental mechanistic grounds. The micrometeorological correction is based on aerodynamic mechanisms and shows no correlation to drivers of biological activity. Conversely, the biological correction is based on climatic responses of organisms and has no physical connection to aerodynamic processes. In those cases where they impose corrections of similar magnitude on the cumulative $F_{c}$ sum, the result is due to a serendipitous similarity in scale but has no clear mechanistic explanation.
\end{abstract}

Key words: AmeriFlux; annual cumulative NEE; complex topography; drainage flows; eddy flux tower; friction velocity; horizontal advection; Niwot Ridge, Colorado, USA; vertical advection.

\section{INTRODUCTION}

During the past decade, tower flux networks have flourished for the purpose of quantifying surfaceatmosphere $\mathrm{CO}_{2}$ exchange. Expectations are high that

Manuscript received 31 May 2006; revised 5 June 2007; accepted 24 July 2007. Corresponding Editor: H. P. Schmid. For reprints of this Invited Feature, see footnote 1, p. 1338.

${ }^{6}$ Corresponding author.

E-mail: Russell.Monson@colorado.edu these networks will provide the empirical constraint required for accurate regional and global carbon budget modeling. FLUXNET, the global articulation of tower flux networks on six continents, includes hundreds of sites each using the eddy covariance approach to measure net ecosystem $\mathrm{CO}_{2}$ exchange (NEE) (Baldocchi et al. 2001; FLUXNET information available online). ${ }^{7}$ The

${ }^{7}\langle$ http://daac.ornl.gov/FLUXNET/〉 
eddy covariance approach is most accurate when applied to ecosystems with flat topography and homogeneous vegetation (Baldocchi 2003). In cases where these criteria cannot be met, extensive characterization of the local wind and $\mathrm{CO}_{2}$ fields must be conducted in order to satisfy the requirement for conservation of mass in the local carbon budget. Few of the FLUXNET sites currently in use meet the topographic and vegetation criteria required to permit accurate $\mathrm{CO}_{2}$ budgeting. As a result, significant uncertainties surround reported estimates of NEE and a variety of observational approaches have been deployed to characterize the mean $\mathrm{CO}_{2}$ fluxes that most often lead to errors (Goulden et al. 1996, Lee 1998, Finnigan 1999, Baldocchi et al. 2000, Paw U et al. 2000, Yi et al. 2000, Lee and $\mathrm{Hu}$ 2002, Massman and Lee 2002, Aubinet et al. 2003, Acevedo et al. 2004, Feigenwinter et al. 2004, Staebler and Fitzjarrald 2005, Marcolla et al. 2005, Wang et al. 2005). As eddy flux networks become increasingly more utilized to provide the observational constraint on regional and global carbon models, it will be important to quantify and reduce these uncertainties. This will be especially important in regions, such as the western continental United States, where over half of the annual carbon sequestration occurs in ecosystems with hilly or mountainous terrain (Schimel et al. 2002).

The two most significant components of the local $\mathrm{CO}_{2}$ budget that are often ignored in eddy covariance studies are the fluxes due to horizontal and vertical motions of the mean wind acting across spatial gradients in the mean $\mathrm{CO}_{2}$ concentration. The advective fluxes that result from these interactions are caused by hills and discontinuities in the earth's surface, which tend to channel winds in a terrain-specific manner, and in the spatial distribution of plant communities and soil types, which cause spatial gradients in $\mathrm{CO}_{2}$ concentration. In the past three years, several studies have been published that report advective $\mathrm{CO}_{2}$ fluxes at specific tower sites and assess the importance of these fluxes to the overall estimate of NEE (Aubinet et al. 2003, Acevedo et al. 2004, Feigenwinter et al. 2004, Staebler and Fitzjarrald 2004, Marcolla et al. 2005). One conclusion that can be drawn from these studies is that the dynamics and magnitudes of the advective fluxes are site specific. In a sloping mixed forest site in Belgium, Aubinet et al. (2003) observed evidence of horizontal and vertical advective fluxes that offset each other in magnitude and mathematical sign, resulting in minimal influence on the calculated NEE. Staebler and Fitzjarrald (2004) showed that, at a deciduous forest site in the northeastern United States, the estimated vertical advective flux was negligible, but the horizontal advective flux was significant, and could account for, on average, a $33 \%$ overestimation of $\mathrm{CO}_{2}$ uptake in the NEE term when advective fluxes are ignored. In a sloping spruce forest in Germany, Feigenwinter et al. (2004) estimated that the vertical and horizontal advective fluxes were opposite in sign and almost exactly canceled each other, indicating little influence on measured NEE values. In a mixed forest in the Italian Alps, Marcolla et al. (2005) observed a large contribution to NEE from positive, vertical advective fluxes at low surface-friction velocities $\left(u_{*}\right)$, and a large contribution from positive, horizontal advective fluxes at high $u_{*}$. In all of these studies, the influence of the advective terms on the estimated total net $\mathrm{CO}_{2}$ flux is highly uncertain due to the difficulties of measuring small gradients in the mean wind and $\mathrm{CO}_{2}$ concentration in the context of high spatial and temporal variability. Clearly, there is much more work to be done on the issue of advective fluxes, both in the development of observational approaches and the formulation of generalizations, to the extent that general theories can be developed.

In this study, we describe an experiment that utilized various combinations of four towers at a single site with complex terrain in the Rocky Mountains of Colorado. We used vertical profiles of wind speed and $\mathrm{CO}_{2}$ concentration to experimentally define a control volume, within which we estimated the horizontal and vertical advective fluxes during selected campaigns over a threeyear period. We observed a relation between both types of advective fluxes and $u_{*}$, which we used to correct the existing six-year NEE record for the site, and we compared this "micrometeorological correction" to the traditional "biological correction" that is derived from modeled values of the relation between NEE and soil temperature. We used this analysis to define the uncertainties that exist in the NEE record for this site due to various assumptions that have been made concerning the accuracy of fluxes measured during stable, nighttime periods.

\section{Materials And Methods}

\section{Site description}

The studies were conducted at the Niwot Ridge AmeriFlux site in the Roosevelt National Forest of Colorado $\left(40^{\circ} 1^{\prime} 58.4^{\prime \prime} \mathrm{N}, 105^{\circ} 32^{\prime} 47^{\prime \prime} \mathrm{W}, 3050 \mathrm{~m}\right.$ elevation), approximately $25 \mathrm{~km}$ west of Boulder, Colorado (USA) and $8 \mathrm{~km}$ east of the continental divide (see Plate 1). Predominant winds are from the west (Brazel and Brazel 1983), flowing downslope. Summertime meteorology produces valley-mountain airflows, with thermalinduced, near-surface upslope winds from the east occurring during the morning and afternoon (Turnipseed et al. 2004). The site is characterized by a west-toeast slope of 5-7\% and covered by a subalpine forest (recovering from logging $100+$ years ago). The forest is uniform for $2 \mathrm{~km}$ to the west and $300-400 \mathrm{~m}$ to the east beyond which the slope increases to $10-13 \%$. Subalpine fir (Abies lasiocarpa), Engelmann spruce (Picea engelmanii), and lodgepole pine (Pinus contorta) dominate the area. The mean canopy height is $11.4 \mathrm{~m}$ and estimated displacement height is $7.8 \mathrm{~m}$ (Monson et al. 2002, Turnipseed et al. 2002, 2003, Yi et al. 2005). 


\section{Theory}

The conservation equation for a scalar quantity $c$ (in this case, $\mathrm{CO}_{2}$ molar mixing ratio) is

$$
\left(\frac{\partial \bar{c}}{\partial t}+\bar{u} \frac{\partial \bar{c}}{\partial x}+\bar{w} \frac{\partial \bar{c}}{\partial z}+\frac{\partial \overline{u^{\prime} c^{\prime}}}{\partial x}+\frac{\partial \overline{w^{\prime} c^{\prime}}}{\partial z}\right)=\bar{S}_{c}
$$

where $x$ is aligned with the horizontal mean wind direction, $z$ is perpendicular to the long-term average stream line (nearly perpendicular to the local terrain surface), and $u$ and $w$ are the respective components of velocity in the $x$ and $z$ coordinates; an overbar denotes a Reynolds average, $\overline{u^{\prime} c^{\prime}}$ and $\overline{w^{\prime} c^{\prime}}$ are the time-averaged turbulent fluxes of the scalar in the $x$ and $z$ coordinates, respectively; $\bar{S}_{c}$ is a $\mathrm{CO}_{2}$ source term, which is nonnegligible only within the canopy. Integrating from the ground to a reference measurement height $\left(Z_{r}\right)$ allows us to define the overall $\mathrm{CO}_{2}$ flux $\left(F_{c}\right)$ as

$$
\begin{aligned}
F_{c} & \equiv \int_{0}^{Z_{r}} \bar{S}_{c} d z+\left(\overline{w^{\prime} c^{\prime}}\right)_{z=0} \\
& =\int_{0}^{Z_{r}} \frac{\partial \bar{c}}{\partial t} d z+\left(\overline{\mathrm{I}} \frac{\left(\overline{w^{\prime} c^{\prime}}\right.}{{ }_{\mathrm{II}}} Z_{Z_{r}}+\int_{0}^{Z_{r}} \bar{u} \frac{\partial \bar{c}}{\partial x} d z+\int_{0}^{Z_{I}}{ }_{\mathrm{IV}}^{\bar{w}} \frac{\partial \bar{c}}{\partial z} d z .\right.
\end{aligned}
$$

Once again, stating that scalar $c$ in this case represents atmospheric $\left[\mathrm{CO}_{2}\right]$, Term $\mathrm{I}$ is the change rate of $\mathrm{CO}_{2}$ storage, Term II is the eddy flux at height $Z_{r}$, Term III is the horizontal advective $\mathrm{CO}_{2}$ flux $\left(F_{\text {hadv }}\right)$, and Term IV is the vertical advective $\mathrm{CO}_{2}$ flux $\left(F_{\text {vadv }}\right)$. The overall $\mathrm{CO}_{2}$ flux $\left(F_{c}\right)$ is often taken as congruent to NEE. In Eq. 2 , we ignored the divergence term of the horizontal turbulent flux because this term is negligible compared to the vertical turbulent flux, provided that the length of the footprint of the turbulent flux measurement is much larger than $Z_{r}$ (Yi et al. 2000) (in our case, the ratio of the flux footprint to $Z_{r}$ is approximately $10: 1$; see Turnipseed et al. 2003).

\section{Experimental design and instrumentation}

Using a multiple tower array, we measured all terms on the right-hand side of Eq. 2 (Fig. 1). The storage flux (Term I) for the canopy space below the eddy flux sensors was calculated using six vertical inlets on the East Tower, obtaining a time-averaged mean for each level for each 30-minute averaging period, summing all levels, and then subtracting this result from the sum measured in the previous 30-minute period (see Monson et al. 2002). The eddy flux (Term II) was measured at the East Tower as previously reported (Monson et al. 2002). Measurements of Terms III and IV were conducted through vertical profiling of $\mathrm{CO}_{2}$ concentration and wind speed on four towers, two of which extended to at least twice the height of the canopy (the East Tower at $21.5 \mathrm{~m}$ and the West Tower at $33 \mathrm{~m}$ ), and two of which extended to nearly the top of the canopy (the North and South towers each at $8 \mathrm{~m}$ ). For various reasons, we were only able to use three of the four towers in any

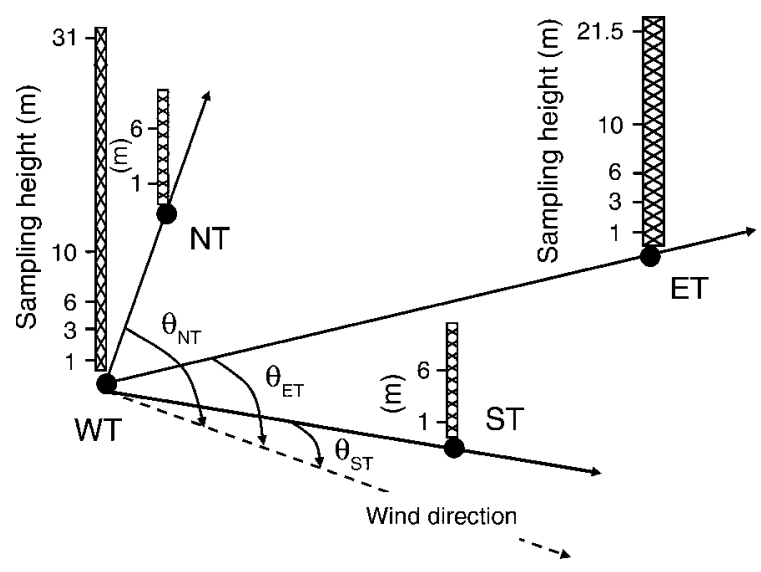

FIG. 1. Locations of the four towers used in the study to determine the $\mathrm{CO}_{2}$ concentration gradient. The angle $\theta_{x x}$ was used to decide which pair of towers to use at any given mean wind direction for any given 30-minute averaging period. The heights used for vertical profiling of $\mathrm{CO}_{2}$ concentration and wind speed are shown for each tower. Abbreviations are WT, West Tower; ET, East Tower; ST, South Tower; and NT, North Tower.

measurement campaign. The towers thus served to triangulate a "control volume" for determination of the $\mathrm{CO}_{2}$ mass balance. Our design included use of a single infrared $\mathrm{CO}_{2}$ analyzer (IRGA; LiCor 7000, LiCor, Lincoln, Nebraska, USA) for all inlets on all towers. From this point forward, we refer to the towers as WT, ET, ST, and NT for the west, east, south and north towers, respectively.

An automated system was designed to sample air from various heights on the towers and automatically calibrate the IRGA. We conducted measurements at 1 , $3,6,10$, and either 21.5 or $31 \mathrm{~m}$ on the WT and ET, and at 1 and $6 \mathrm{~m}$ on the NT and ST. The calibration interval was every $2 \mathrm{~h}$ using an ultra-high purity $\mathrm{N}_{2}$ gas $(<0.1$ ppm $\mathrm{CO}_{2}$ [parts $\mathrm{CO}_{2}$ per million parts $\mathrm{N}_{2}$ ]) for a zero and a NOAA (Mational Oceanic and Atmospheric Administration, Climate Modeling and Diagnostics Laboratory, Boulder, Colorado) referenced span gas ( $\sim 400$ ppm $\mathrm{CO}_{2}$ in air). A data logger (model 10X; Campbell Scientific, Logan, Utah, USA) was used to control the system, as well as log and archive data. Air was constantly pulled through each line of the system at a flow rate of $2 \mathrm{~L} / \mathrm{min}$. The 14 lines were sequentially sampled for a period of $30 \mathrm{~s}$ each. Signals $(1 \mathrm{~Hz})$ from the IRGA $\left(\mathrm{CO}_{2}\right.$ concentration, cell pressure, and temperature) were averaged for the last $15 \mathrm{~s}$ of the sampling interval to allow for purging of the previous sample and to allow for pressure to equilibrate in the IRGA sample cell. The sample air stream was temperature controlled by a constant-temperature water bath just before reaching the thermally insulated IRGA. Each sample line was equipped with a 4-L mixing volume (glass vessels with offset in/out ports) to introduce a time constant of more than 2 minutes. This had the effect of 
homogenizing the sample thereby reducing the effects of short-term variability or sample noise.

Sample lines running from the towers to the glass mixing vessels consisted of $6.4 \mathrm{~mm}$ (inner diameter) Teflon tubing with an attached $1-\mu \mathrm{m}$ pore Teflon filter followed by a $0.6 \mathrm{~mm}$ flow restrictor. The pressure drop behind the filter and restrictor led to a decrease in relative humidity as sample air temperature re-equilibrated with that of the environment, thereby preventing formation of water or ice in the lines. The IRGA cell pressure was maintained at $20 \mathrm{kPa}$ below ambient $(\sim 70$ $\mathrm{kPa})$. The WT and ET were instrumented with twodimensional sonic anemometers (model 425A; Handar, Inc., Sunnyvale, California, USA) at 3, 6, and $10 \mathrm{~m}$, and three-dimensional sonic anemometers (Campbell Scientific, model CSAT-3) at 1 and $31 \mathrm{~m}$ (WT) or $21.5 \mathrm{~m}$ (ET). The same type of two-dimensional sonic anemometer was located at 1 and $6 \mathrm{~m}$ on the NT and ST. Wind direction determined with the two-dimensional anemometers was calculated from the raw data output from the anemometers. Wind and temperature data were sampled at $1 \mathrm{~Hz}$ frequency from which 30-minute averages were computed and archived. In an "end-toend" test of the system, we introduced gas standards of known $\mathrm{CO}_{2}$ concentrations into each inlet to assess repeatability of concentration measurements and time for gas transfer. The maximum system response time was determined to be $134 \mathrm{~s}$ and measurement accuracy was $<0.3$ ppm.

\section{Procedures for calculating $F_{\mathrm{hadv}}$ and $F_{\mathrm{vadv}}$}

Values for $\bar{w}$ were estimated by planar-fit coordinate rotation (Wilczak et al. 2001), as explained in Turnipseed et al. (2003). From our past studies (Turnipseed et al. 2004, Yi et al. 2005), we have concluded that nighttime katabatic flows at the tower site are most likely stratified, with flows beneath the canopy uncoupled from those above the canopy. Following this conclusion, we assumed that $F_{\text {vadv }}$ originated from that part of the canopy above a hypothesized within-canopy stable layer (validated by $\mathrm{SF}_{6}$ tracer experiments, see $\mathrm{Yi}$ et al. [2005]), and we used wind speed data from the 21.5 $\mathrm{m}$ height and the vertical $\left[\mathrm{CO}_{2}\right]$ gradient between $10 \mathrm{~m}$ and $21.5 \mathrm{~m}$ to calculate $F_{\text {vadv }}$ according to Lee (1998):

$$
F_{\mathrm{vadv}}=\bar{w}_{21.5}\left(\bar{c}_{21.5}-\langle\bar{c}\rangle\right)
$$

where $\langle\bar{c}\rangle$ is the column averaged $\left[\mathrm{CO}_{2}\right]$ between 10 and $21.5 \mathrm{~m}$. Eq. 3 carries the implicit assumption of linear decay in $\bar{w}$ as a function of height between 10 and 21.5 $\mathrm{m}$, with $\bar{w}=0$ at $10 \mathrm{~m}$.

When calculating the horizontal advective flux $\left(F_{\text {hadv }}\right)$, we treated the control volume as being vertically stratified with potentially independent horizontal flows. We calculated the horizontal wind speed and direction of the horizontal $\mathrm{CO}_{2}$ gradient independently for each of four heights $(1,3,6$, and $10 \mathrm{~m})$. This meant that in many of the averaging periods the $\left[\mathrm{CO}_{2}\right]$ gradient at one height was determined from a different pair of towers than the
$\left[\mathrm{CO}_{2}\right]$ gradient at a different height. In order to calculate the overall $F_{\text {hadv }}$ for each 30 -minute averaging period, we assumed that each measurement height was centered on a horizontal slab extending through the control volume. The value of $F_{\text {hadv }}$ was then determined by summing the individual fluxes of the four horizontal slabs. If the wind direction did not exactly coincide with the axis running through two of the towers (which was most of the time), then $F_{\text {hadv }}$ was determined as

$$
\begin{aligned}
F_{\mathrm{hadv}}= & \int_{0}^{12} \bar{u} \frac{\partial \bar{c}}{\partial x} d z \\
= & \left.\int_{0}^{12} \bar{u} \frac{\partial \bar{c}}{\partial r}\right|_{i \mathrm{~T}} \cos \theta_{i \mathrm{~T}} d z \\
\approx & \bar{u}_{1 m}\left(\frac{\Delta c}{\Delta r}\right)_{1 m}^{\mathrm{WT}-i \mathrm{~T}} \cos \theta_{i \mathrm{~T}} \times 2 \\
& +\bar{u}_{3 m}\left(\frac{\Delta c}{\Delta r}\right)_{3 m}^{\mathrm{WT}-\mathrm{ET}} \cos \theta_{\mathrm{ET}} \times 2 \\
& +\bar{u}_{6 m}\left(\frac{\Delta c}{\Delta r}\right)_{6 m}^{\mathrm{WT}-i \mathrm{~T}} \cos \theta_{i \mathrm{~T}} \times 4 \\
& +\bar{u}_{10 m}\left(\frac{\Delta c}{\Delta r}\right)_{10 m}^{\mathrm{WT}-\mathrm{ET}} \cos \theta_{\mathrm{ET}} \times 4
\end{aligned}
$$

where $\theta_{i \mathrm{~T}}$ is the angle between the prevailing wind direction and the primary axis of the $\mathrm{CO}_{2}$ gradient, $i=$ $\mathrm{E}, \mathrm{N}, \mathrm{S}, \bar{u}_{h}$ is wind speed at height $h$ measured at WT, $(\Delta c / \Delta r)_{h}^{\mathrm{WT}-i \mathrm{~T}}$ is the $\mathrm{CO}_{2}$ gradient between $\mathrm{WT}$ and $i \mathrm{~T}$ at height $h$. Given the geometry of the control volume, the measured horizontal $\mathrm{CO}_{2}$ gradient is available in three possible directions relative to any single tower at 1 and 6 $\mathrm{m}$ (measurements were available at all towers at these heights) and only one direction at 3 and $10 \mathrm{~m}$ (measurements were only available at the WT and ET for these heights) (Fig. 1). There were some cases in which the experimental design did not allow us to get a close match between the $\left[\mathrm{CO}_{2}\right]$ gradient and wind direction; that is, $\theta$ did not line up well with the $\left[\mathrm{CO}_{2}\right]$ gradients we were capable of measuring. In recognition of this, we eliminated extreme values of $\theta$ by excluding averaging periods when $|\cos \theta|<0.8$ (i.e., when $|\cos \theta|>$ $36.9^{\circ}$ ). For $94 \%$ of those periods when we did observe wind directions within the acceptable bounds of the cosine criterion, the wind direction was the same at the two towers used to quantify $F_{\text {hadv }}$ (data not shown). Thus, there was little evidence of changes in wind direction within the control volume. We have validated our cosine-referenced one-dimensional approach against direct observations of the wind flows and advective $\mathrm{CO}_{2}$ fluxes in a true two-dimensional analysis ( $x$ and $y$ spatial coordinates) using various combinations of towers for a period during the summer of 2001 (see Appendix). The analysis revealed that cross-wind advective fluxes within the control volume were small, and contributed negli- 
TABLE 1. Nocturnal vertical velocity $(\bar{w}$, mean $\pm \mathrm{SE})$ and standard deviation of the wind direction $\left(\sigma_{\theta}\right.$, mean \pm SE) as a function of height above the ground.

\begin{tabular}{ccc}
\hline \hline Height $(\mathrm{m})$ & $\bar{w}(\mathrm{~m} / \mathrm{s})$ & $\sigma_{\theta}$ (degrees) \\
\hline 1 & $-0.0015 \pm 0.0003$ & $49.1 \pm 0.4$ \\
3 & $-0.0050 \pm 0.0008$ & $51.5 \pm 0.6$ \\
21.5 & $0.0100 \pm 0.0010$ & $27.6 \pm 0.6$ \\
\hline
\end{tabular}

Note: The data were taken for the entire year from 1 November 2001 to 31 October 2002.

gibly to fluxes estimated by the cosine-referenced approach.

In practice, for each 30-minute averaging period, we progressed through each of the following steps. (1) We determined if $\theta$ and the direction of the $\left[\mathrm{CO}_{2}\right]$ gradient were acceptable (i.e., $|\cos \theta| \geq 0.8$ ) at all heights; if not, we eliminated the period from further analysis. (2) We determined if $\theta$ was along the WT-ET axis at both the 3 and $10 \mathrm{~m}$ heights $(|\cos \theta| \geq 0.8)$; if not, we eliminated the period from further analysis. (3) We determined the relevant towers to use for the 1 and $6 \mathrm{~m}$ heights, depending on $\theta$ at those heights. (4) We calculated the value of $F_{\text {hadv }}$ using data summed from all heights. (5) We calculated $F_{\text {vadv }}$.

We analyzed a total of 23424 30-minute periods using a 134-day period (between day of the year [DOY] 178 and 312) in 2001 using three towers (ET, WT, and ST), a 170-day period (between DOY 151 and 321) in 2002 using three towers (ET, WT, and NT), and a 184-day period (between DOY 146 and 330) in 2003 using three towers (ET, WT, and NT). Additionally, we analyzed data from 816030 -minute periods using only two towers (the WT and ET), for those periods when the prevailing wind traversed the west-east axis, for a 170-day period (between DOY 7 and 177) during the winter of 2001. Thus, the total number of 30 -minute periods we analyzed was 31584 . The reason we only used three towers in 2001 is that the NT did not exist until 2002. The reason we only used three towers in 2002 and 2003 is that analysis of the data from the ST revealed that new lines installed after 2001 to the ST were affected by small leaks in their fittings; we did not have full confidence in the ST data after the 2001 campaign and we dropped it from subsequent analyses. After applying all selective criteria we were able to use 503030 -minute periods (16\% of all possible periods) for the calculation of $F_{\text {hadv }}$. Many of the periods that were excluded from the $F_{\text {hadv }}$ analysis were characterized by instrument failures $(38 \%$ of the periods). Additionally, many of the periods that were excluded did not meet the $|\cos \theta| \geq 0.8$ criterion and have data from all four measurement heights $(46 \%$ of the periods). After applying all selective criteria we were able to use 960930 -minute periods (30\% of all possible periods) for the calculation of $F_{\mathrm{vadv}}$. Most of the periods eliminated for evaluation of $F_{\mathrm{vadv}}$ occurred during the daytime hours, when $F_{\text {vadv }}$ was not observed due to turbulent mixing. Overall, we estimated that we were able to quantify $F_{\text {hadv }}$, and $F_{\text {vadv }}$ in $48 \%$ of those nighttime periods that exhibited significant advective fluxes.

\section{RESUlts}

Estimation of the horizontal and vertical advective fluxes

We calculated vertical profiles in $\bar{w}$ and the standard deviation of wind direction $\left(\sigma_{\theta}\right)$ for three heights (Table 1). Beneath the canopy, at 1 and $3 \mathrm{~m}$, the mean $\bar{w}$ for the entire year was slightly negative (downward bias) and smaller in magnitude than above the canopy, at $21.5 \mathrm{~m}$, where $\bar{w}$ was positive (upward bias) and larger in magnitude. The averaged $\bar{w}$ values for all heights were below the offset accuracy $(0.04 \mathrm{~m} / \mathrm{s})$ of the sonic anemometers we used for measurement. However, these one-year averages were taken from 30-minute averaged $\bar{w}$ values, $45 \%$ of which were higher than the $0.04 \mathrm{~m} / \mathrm{s}$ offset accuracy. Thus, while the averages are low, we have confidence that they reflect accurate trends of uncoupling in $\bar{w}$ below and above the canopy. In our analysis of data during 2001-2002, the standard deviation of wind direction $\left(\sigma_{\theta}\right)$ beneath the canopy was twice as high as above the canopy (Table 1). We have used the results reported in Table 1, and those of our past studies (Turnipseed et al. 2004, Yi et al. 2005) to justify our characterization of the control volume as vertically stratified during the night, and that $F_{\text {vadv }}$ is most likely to originate from near the top of the canopy.

During those periods when the wind flowed between the WT and ET at all four heights, we determined the magnitude of the mean $\left[\mathrm{CO}_{2}\right]$ gradient. Gradients were larger during the night than the day at all heights (Fig. 2). At night, the largest gradients were observed at $6 \mathrm{~m}$, with smaller, but significant gradients at 1 and $3 \mathrm{~m}$.

In the current study, we estimated the horizontal $\left[\mathrm{CO}_{2}\right]$ gradient independently from measurements at four heights for the purposes of evaluating $F_{\text {hadv }}$. This

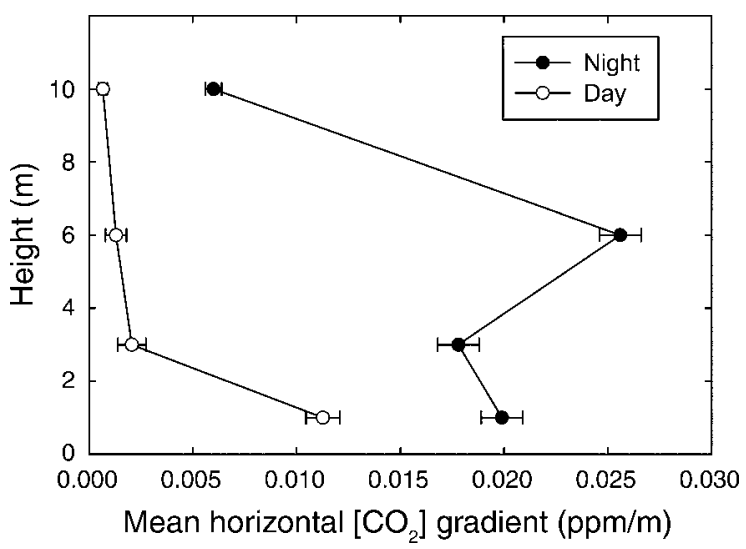

FIG. 2. Profiles of the mean horizontal $\left[\mathrm{CO}_{2}\right]$ gradient (measured as parts $\mathrm{CO}_{2}$ per million parts air) along the WT-ET direction in the summer. The number of 30 -minute averaging periods used in each profile is 1709 for the night, and 1001 for the day. Error bars indicate \pm SD of the mean. 

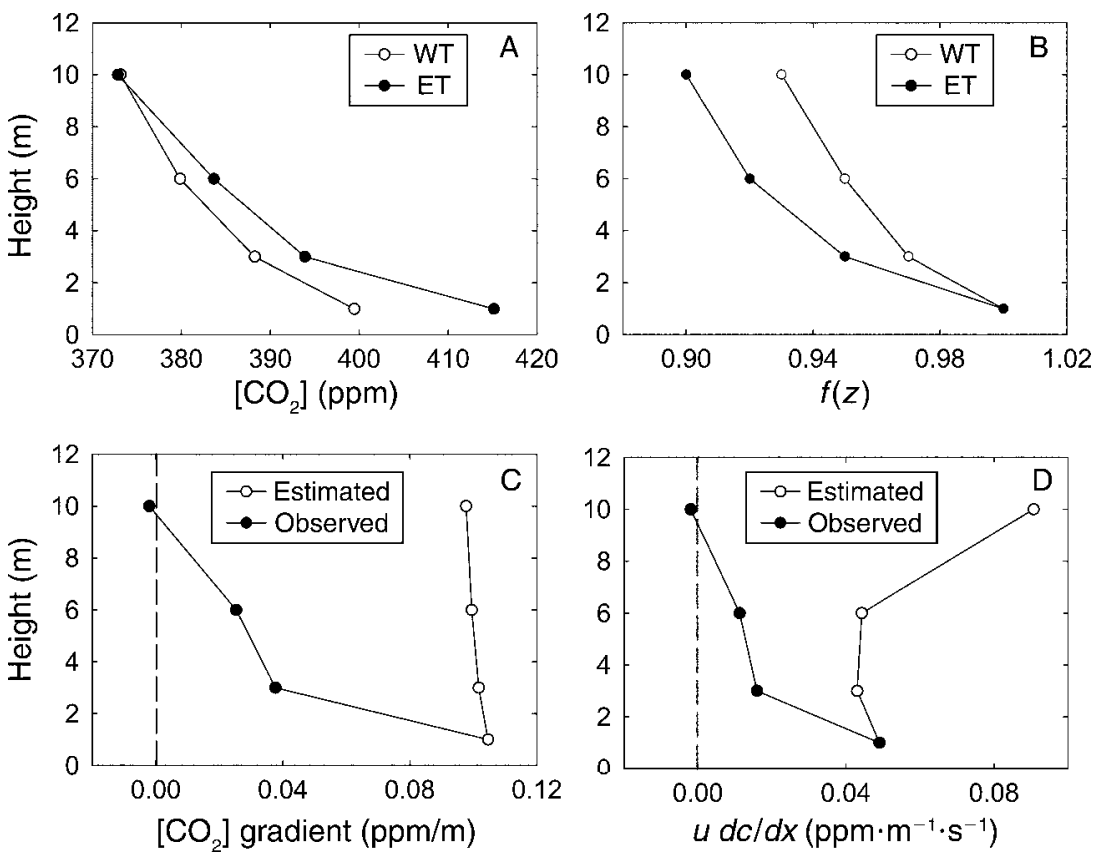

FIG. 3. (A) $\mathrm{CO}_{2}$ profiles at ET and WT; (B) relative distribution functions of $\mathrm{CO}_{2}$ at $\mathrm{ET}$ and WT; (C) horizontal $\mathrm{CO}_{2}$ gradients; and (D) horizontal advection $\mathrm{u} d c / d x$. The "estimated" horizontal $\mathrm{CO}_{2}$ gradients (open circles in $\mathrm{C}$ ) and $\mathrm{u} d c / d x$ (open circles in D) were derived based on the relative distribution function of $\mathrm{CO}_{2}$ at WT and $\mathrm{CO}_{2}$ concentration at $1 \mathrm{~m}$ measured at ET. The $u_{*}$ for this case is $0.36 \mathrm{~m} / \mathrm{s}$. Data are from 05:30 hours Mountain Standard Time on 24 June 2002. Variables are: $f$, frequency; $z$, height above the ground (in meters); $u$, horizontal wind speed (in m/s); $u_{*}$, surface friction velocity $(\mathrm{m} / \mathrm{s}) ; c$, concentration of $\mathrm{CO}_{2}(\mathrm{ppm}$ $\mathrm{CO}_{2}$ per million parts of air).

approach differs from some of the past approaches that have been used (e.g., Aubinet et al. 2003, Staebler and Fitzjarrald 2004), in which the vertical profile of $\left[\mathrm{CO}_{2}\right]$ concentration is measured on one tower and used to construct a $\mathrm{CO}_{2}$ distribution function, which is then combined with measurements of the horizontal $\left[\mathrm{CO}_{2}\right]$ gradient at a single height to infer the vertical profile of the $\left[\mathrm{CO}_{2}\right]$ gradient. This single-tower approach might be termed the "similarity approach" because it contains the implicit assumption that the vertical profile of the horizontal $\left[\mathrm{CO}_{2}\right]$ gradient (and wind speed) transfers with spatial similarity through the control volume. Using our multiple-tower configuration we tested the similarity approach for our site. We used 30-minute averaging periods (4300 total periods from both day and night) in which the wind direction at all four levels (1, 3, 6 , and $10 \mathrm{~m}$ ) was along the WT-ET axis, and which satisfied the criterion $|\cos \theta| \geq 0.8$. The vertical distribution function of $\mathrm{CO}_{2}$ concentration is defined as $f_{i \mathrm{~T}}(z)=c_{i \mathrm{~T}}(z) / c_{i \mathrm{~T}}\left(z_{1}\right)$, where $i$ refers to a specific tower (e.g., ET, WT), $c_{i \mathrm{~T}}(z)$ is the $\mathrm{CO}_{2}$ concentration measured at height $z$ from the $i$ tower, and $z_{1}$ is a reference height of $1 \mathrm{~m}$. Two vertical distribution functions, $f_{\mathrm{WT}}(z)$ and $f_{\mathrm{ET}}(z)$, were calculated from the two observed $\mathrm{CO}_{2}$ profiles at the WT and ET, respectively. The $\mathrm{CO}_{2}$ profile at the ET, when deduced from measurements at the WT using the similarity approach, is equal to $c_{\mathrm{ET}}\left(z_{1}\right) f_{\mathrm{WT}}(z)$. The $\left[\mathrm{CO}_{2}\right]$ gradient at the two towers and the distribution functions are shown in Fig. 3A, B, respec- tively. The difference between the predicted profile of the $\left[\mathrm{CO}_{2}\right]$ gradient using the similarity approach, and the observed $\left[\mathrm{CO}_{2}\right]$ gradient, increased with height (Fig. 3C). Overestimation of the horizontal $\left[\mathrm{CO}_{2}\right]$ gradient with the similarity approach caused $F_{\text {hadv }}$ to be also overestimated (Fig. 3D). The particular example shown in Fig. 3 is for a case in which the surface friction velocity $\left(u_{*}\right.$; measured at $21.5 \mathrm{~m}$ on the ET) was $0.36 \mathrm{~m} / \mathrm{s}$. When analyzed as a function of $u_{*}$, we estimated that, on average, the similarity approach caused a 1.01 $\mu \mathrm{mol} \cdot \mathrm{m}^{-2} \cdot \mathrm{s}^{-1}$ underestimation of $F_{\text {hadv }}$ at $u_{*}<0.18$ $\mathrm{m} / \mathrm{s}$, a $1.28\left(\mu \mathrm{mol} \cdot \mathrm{m}^{-2} \cdot \mathrm{s}^{-1}\right)$ overestimation of $F_{\text {hadv }}$ when $0.18 \leq u_{*} \leq 0.89 \mathrm{~m} / \mathrm{s}$, and no significant error in the estimation of $F_{\text {hadv }}$ when $u_{*}>0.89 \mathrm{~m} / \mathrm{s}$ (Fig. 4).

\section{Patterns in $\mathrm{F}_{\text {hadv }}$ and $\mathrm{F}_{\text {vadv }}$ and influence on $\mathrm{F}_{c}$}

When observation periods were pooled for the entire three-year experiment, there were clear correlations among, $F_{\text {hadv }}, F_{\text {vadv }}$, and $u_{*}$ (determined at $21.5 \mathrm{~m}$ on the ET; Fig. 5). At low $u_{*}$, values of $F_{\text {hadv }}$ were large and positive, whereas values of $F_{\text {vadv }}$ were large and negative; as $u_{*}$ increased due to increased wind speed and accompanying shear stress, the magnitude of the advective fluxes decreased. In some cases, especially at relatively high $u_{*}$, we observed negative values for $F_{\text {hadv }}$. We binned the observations of advective fluxes into daytime and nighttime periods and into summer and winter seasons in order to gain some insight into seasonal effects. The dependence of $F_{\text {hadv }}$ and $F_{\text {vadv }}$ on 

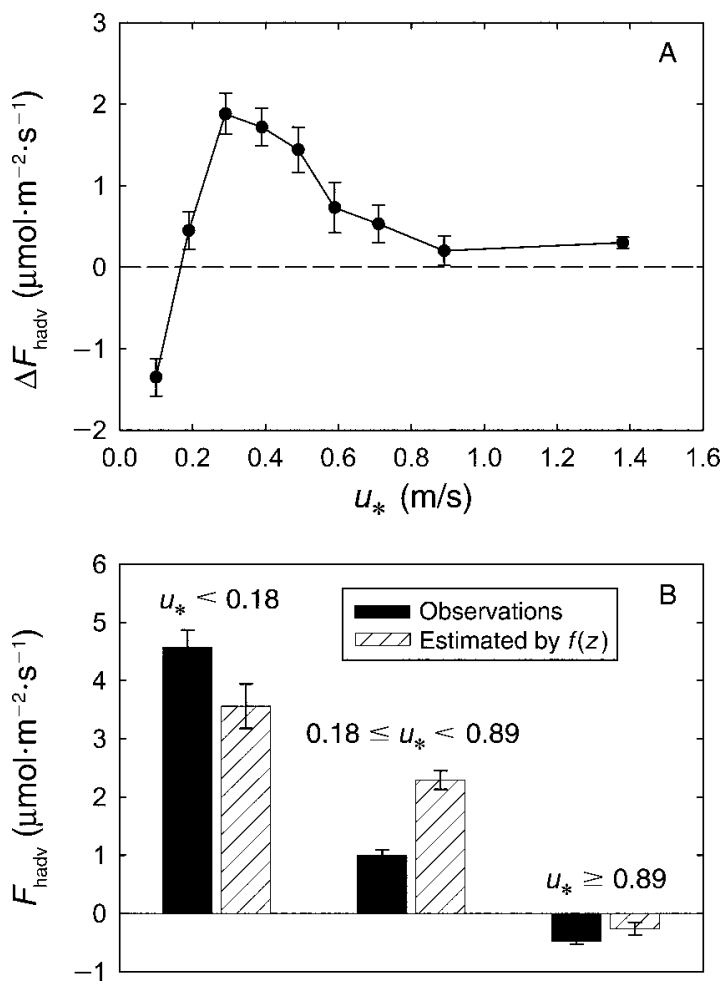

FIG. 4. (A) Difference in the horizontal advection flux $\left(F_{\text {hadv }}\right)$ between observed values and values estimated by the similarity approach as a function of friction velocity $\left(u_{*}\right)$. (B) Comparison of $F_{\text {hadv }}$ between observed values and values estimated by the similarity approach averaged across three different $u_{*}$ ranges. The data used in this analysis were limited to cases in which wind directions at all levels $(1,3,6$, and $10 \mathrm{~m})$ were approximately oriented along a line between WT and ET, i.e., $\left|\cos \theta_{\mathrm{ET}}\right| \geq 0.8$. The number of half-hourly data points at each level was $N=4300$, including daytime and nighttime periods. Error bars are \pm SE.

$u_{*}$ was most obvious during the summer and was highest during nighttime periods. During the winter there remained some dependence of both advective fluxes on $u_{*}$, although it was muted by the fact that the flux rates were low. For summer nighttime periods, the magnitude of $F_{\text {vadv }}$ decreased faster than that of $F_{\text {hadv }}$ with increasing $u_{*}$ and approached zero near $u_{*}=0.4 \mathrm{~m} / \mathrm{s}$. This caused there to be a region of $u_{*}$ values $(\sim 0.3-0.6 \mathrm{~m}$ $\mathrm{s}^{-1}$ ) where $F_{\text {hadv }}$ was positive in value and not balanced by a negative $F_{\text {vadv }}$.

We used the seasonal and diurnal relationships among $F_{\text {hadv }}, F_{\text {vadv }}$, and $u_{*}$ shown in Fig. 5 to evaluate the effect of advective fluxes on the total $\mathrm{CO}_{2}$ flux $\left(F_{c}\right)$ over a sixyear measurement period (Fig. 6A). We have presented several possible approaches to correct the record for the effects of high atmospheric stability, including both micrometeorological and biological strategies. When $F_{c}$ was determined without $F_{\text {hadv }}$ and $F_{\text {vadv }}$ (i.e., with only Terms I and II in Eq. 2), the ecosystem gained carbon from the atmosphere in each of the six years, with cumulative (six-year) C sequestration of $0.733 \mathrm{~kg} \mathrm{C} / \mathrm{m}^{2}$.
Using the traditional, biological $u_{*}$ correction (where a previously determined model is used to replace 30minute averaged $F_{c}$ values observed when $u_{*}$ was below $0.2 \mathrm{~m} / \mathrm{s}$ [see Monson et al. 2002]), the six-year cumulative $\mathrm{C}$ sequestration was estimated to be 0.384 $\mathrm{kg} \mathrm{C} / \mathrm{m}^{2}$ (48\% lower than $F_{c}$ determined with only Terms I and II). With the latter calculation, $F_{c}$ was reduced because low flux rates that occur when the atmosphere is stable are replaced with higher values that are calculated from an exponential respiration model based on soil temperature. Since stable atmospheric conditions occur most often at night, when fluxes reflect respiratory $\mathrm{CO}_{2}$ sources, the higher modeled flux rates estimate lower $\mathrm{C}$ sequestration. We evaluated three cases in which we added advective fluxes to the 30-minute averaged sum of the eddy and storage fluxes calculated as the sum of Terms I and II in Eq. 2. Because we did not have $F_{\text {hadv }}$ and $F_{\text {vadv }}$ for every 30 -minute period in the record, we corrected each period on the basis of observed $u_{*}$, adding the appropriate $F_{\text {hadv }}$ and $F_{\text {vadv }}$ for that $u_{*}$ value based on the data reported in Fig. 5. When we calculated the $\mathrm{CO}_{2}$ flux using only $F_{\text {hadv }}$ combined with Terms I and II (i.e., ignoring $F_{\text {vadv }}$ ), we estimated that the ecosystem would be a net source of $\mathrm{C}$, not a sink, and that the total six-year source would be 0.351 $\mathrm{kg} \mathrm{C} / \mathrm{m}^{2}$. When we used only $F_{\text {vadv }}$ combined with

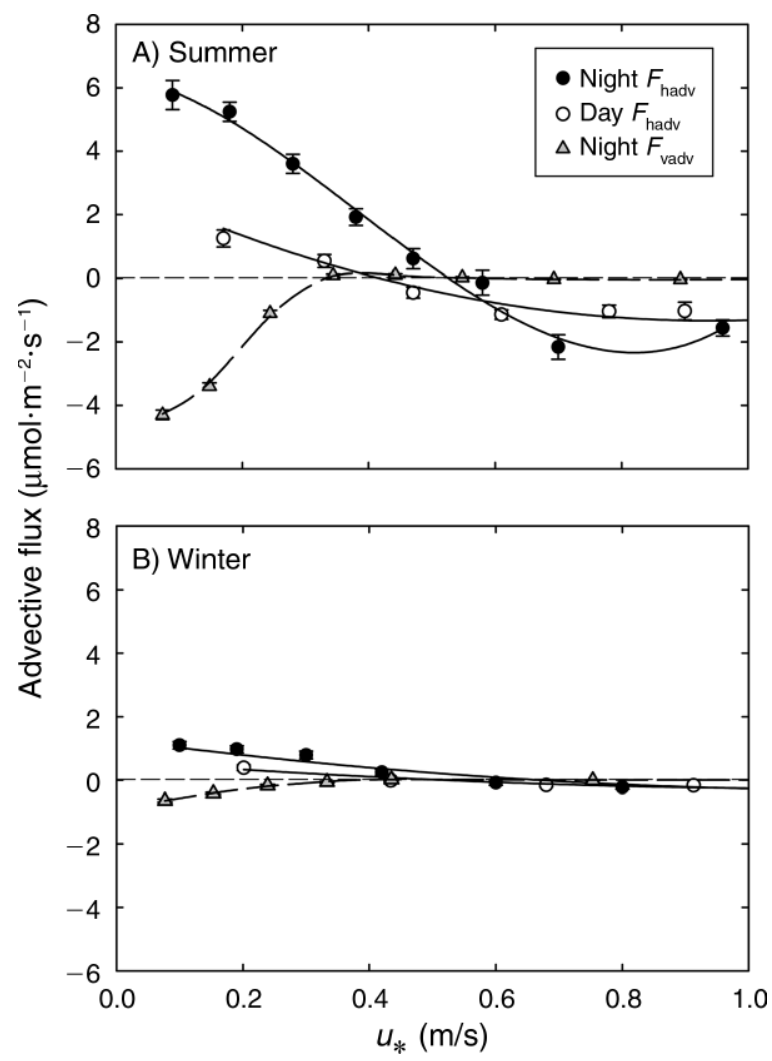

FIG. 5. The binned average of advective fluxes (horizontal, hadv; vertical, vadv) vs. $u_{*}$ in (A) summer and (B) winter. Error bars indicate $\pm \mathrm{SD}$ of the mean. 

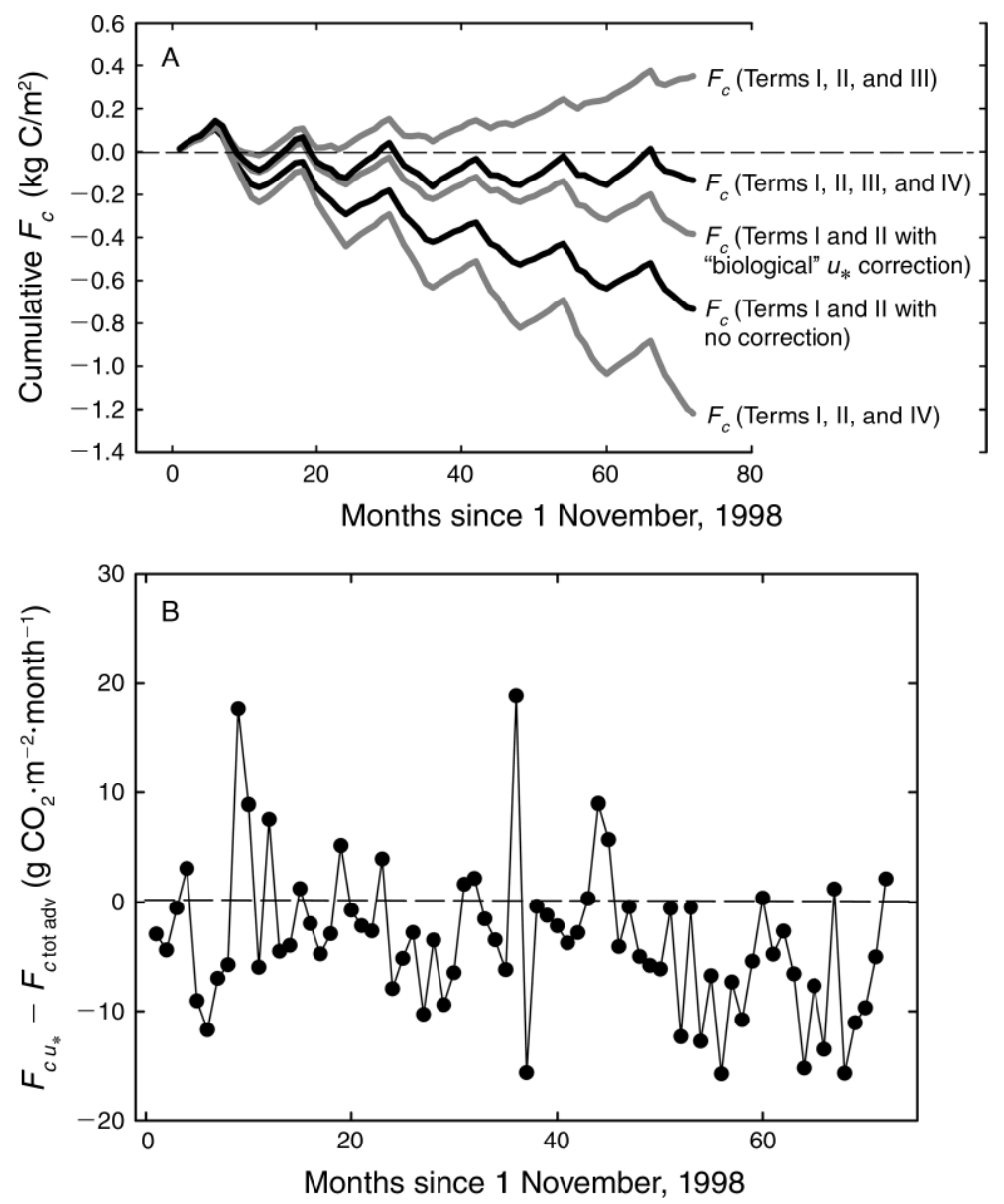

FIG. 6. (A) Cumulative $\mathrm{CO}_{2}$ flux ( $F_{c}$, where $c$ is a scalar quantity) for the six-year period beginning on 1 November 1998 . Negative values reflect net uptake of $\mathrm{CO}_{2}$ from the atmosphere, and positive values reflect net emission of $\mathrm{CO}_{2}$ to the atmosphere. All terms used to calculate each $F_{c}$ scenario are referenced to Eq. 2. Five different scenarios are presented: (1) observed $F_{c}$ with no flux corrections for stable nights (Terms I and II); (2) observed $F_{c}$ with only the traditional "biological" correction (Terms I and II with correction for stable nights using a $u_{*}$ filter set at $0.2 \mathrm{~m} / \mathrm{s}$ and replacement with $F_{c}$ values calculated from the observed correlation between $F_{c}$ and soil temperature above the $u_{*}$ thresholds); (3) observed $F_{c}$ with only the eddy flux, storage flux, and horizontal advective flux (Terms I, II, and III); (4) observed $F_{c}$ with only the eddy flux, storage flux, and vertical advective flux (Terms I, II, and IV); and (5) observed $F_{c}$ with all component fluxes (Terms I, II, III, and IV). (B) Difference in mean monthly cumulative $\mathrm{CO}_{2}$ flux $\left(F_{c}\right)$ determined from the traditional "biological" method using a $u_{*}$ filter $(<0.2 \mathrm{~m} / \mathrm{s})\left(F_{c, u_{s}}\right)$ and that determined from the "micrometeorological" method as the sum of all components of the flux as depicted in Eq. $2\left(F_{c}\right.$ tot adv $)$ (Terms I, II, III, and IV).

Terms I and II (i.e., ignoring $F_{\text {hadv }}$ ), the ecosystem was predicted to once again be a net $\mathrm{C}$ sink and the six-year $\mathrm{C}$ sequestration rate was predicted to be $1.217 \mathrm{~kg} \mathrm{C} / \mathrm{m}^{2}$, a rate that is $66 \%$ higher than that predicted by using only the sum of Terms I and II. Finally, when we calculated the total $\mathrm{CO}_{2}$ flux $\left(F_{c}\right)$ by adding both mean advective terms $\left(F_{\text {hadv }}+F_{\text {vadv }}\right)$ to Terms I and II using each 30-minute period, we estimated a six-year $\mathrm{C}$ sequestration rate that was $0.133 \mathrm{~kg} / \mathrm{m}^{2}$, a rate that was $82 \%$ lower than that predicted using just the sum of Terms I and II. One of the key results to emerge from the analysis of Fig. 6 is that the six-year cumulative NEE (taken as equal to $F_{c}$ in Eq. 2) when determined using our traditional, biological correction (with a $u_{*}$ threshold of $0.2 \mathrm{~m} / \mathrm{s}$ ) varied by $65 \%$ from the cumulative NEE determined using the micrometeorological calculation with $F_{\text {hadv }}$ and $F_{\text {vadv }}$ (in other words taking all four terms on the right-hand side of Eq. 2).

We determined the complete $\mathrm{CO}_{2}$ flux budget for all summer nighttime periods for all measurement campaigns between 1999 and 2004. In other words, we partitioned $F_{c}$ into the four mean component fluxes presented on the right-hand side of Eq. 2. We estimated the total mean flux $\left(F_{c}\right)$ to be $3.75 \pm 0.04 \mu \mathrm{mol} \cdot \mathrm{m}^{-2} \cdot \mathrm{s}^{-1}$. The storage flux (Term I) was estimated to be $0.08 \pm$ $0.01 \mu \mathrm{mol} \cdot \mathrm{m}^{-2} \cdot \mathrm{s}^{-1}$. The mean eddy flux (Term II) was estimated to be $2.37 \pm 0.02 \mu \mathrm{mol} \cdot \mathrm{m}^{-2} \cdot \mathrm{s}^{-1}$. The mean horizontal advective flux (Term III) was estimated to be $2.76 \pm 0.03 \mu \mathrm{mol} \cdot \mathrm{m}^{-2} \cdot \mathrm{s}^{-1}$. The mean vertical advective 


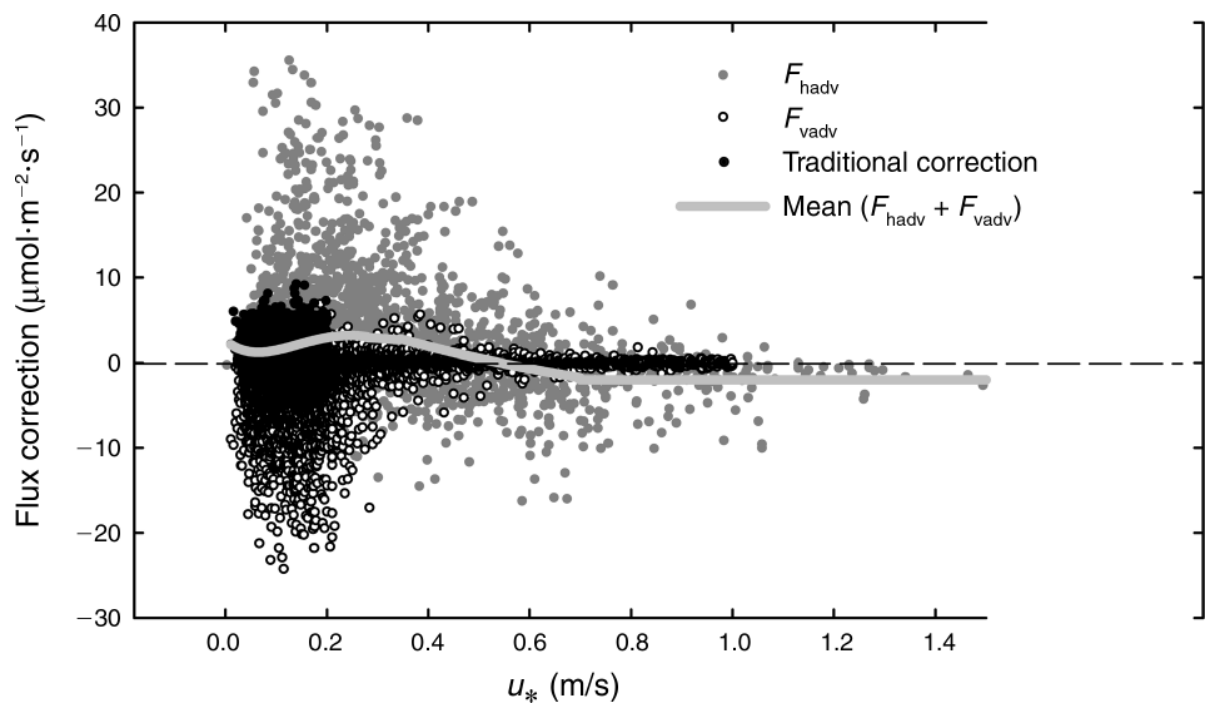

FIG. 7. Comparison of $\mathrm{CO}_{2}$ flux corrections as a function of $u_{*}$ for summer nighttime periods. The term "traditional correction" refers to the method of replacing the sum of Terms I and II in Eq. 2 (i.e., the eddy plus storage fluxes) by a $\mathrm{CO}_{2}$ flux derived from the $F_{c}$ vs. soil temperature relationship for 30-minute periods when $u_{*}$ (determined at $21.5 \mathrm{~m}$ on the ET) was determined to be $<0.2$ $\mathrm{m} / \mathrm{s}$ (see Monson et al. 2002). The "mean" correction was determined as the sum of the vertical and horizontal advective fluxes for each 30-minute period and plotted as a function of the mean $u_{*}$ (determined at $21.5 \mathrm{~m}$ on the ET) for that same period.

flux (Term IV) was estimated to be $-1.46 \pm 0.02$ $\mu \mathrm{mol} \cdot \mathrm{m}^{-2} \cdot \mathrm{s}^{-1}$.

We assessed the difference between cumulative $F_{c}$ determined using the traditional $u_{*}$ correction and that determined with $F_{\text {hadv }}+F_{\text {vadv }}$ for each month of the study (Fig. 6B). When averaged across the entire sixyear period, the differences between the two estimates of monthly cumulative $F_{c}$ were within $10 \%$ of each other. However, there were months when the values diverged considerably. There was no general seasonal pattern in the magnitude of this difference.

To examine the relation between the micrometeorological and biological methods further, we plotted the flux calculations as a function of $u_{*}$ (Fig. 7). The biological correction, using a $u_{*}$ threshold of 0.2 , favored slightly positive flux corrections. The sum of $F_{\text {hadv }}$ and $F_{\text {vadv }}$ tended to be slightly positive (favoring a positive $\left.F_{\text {hadv }}\right)$ across the lowest range of $u_{*}$ values, which fell at the approximate mean of the biological correction.

\section{DisCUSSION}

The most widely used method of measuring net ecosystem $\mathrm{CO}_{2}$ exchange (NEE) involves use of the eddy covariance technique to quantify the $\mathrm{CO}_{2}$ turbulent flux, accompanied with characterization of $\mathrm{CO}_{2}$ storage beneath eddy flux sensors (Goulden et al. 1996). Relying on theoretical arguments, most researchers recognize that this approach is inadequate when turbulent intensity is low, as often occurs in stable nighttime periods. During stable atmospheric periods, turbulent coupling of surface fluxes to the above-canopy eddy covariance sensors at the top of the tower is poor. During these conditions, $\mathrm{CO}_{2}$ can be carried by horizontal and vertical advection on atmospheric flows that are not captured by the eddy flux technique. To correct for this inadequacy, researchers typically filter stable periods from their flux record on the basis of measured $u_{*}$, and replace estimates of NEE during these periods with values obtained from the modeled dependence of NEE on soil temperature. As an alternative, one could make direct observations of the advective fluxes during stable periods, and add those fluxes to the eddy and storage fluxes to obtain a direct measurement of NEE (also taken as $F_{c}$ in Eq. 2). We distinguish these two approaches as the "biological approach," using the $F_{c}$ vs. soil temperature relation, and the "micrometeorological approach," using the direct measurement of all fluxes on the right-hand side of Eq. 2 through micrometeorological methods. These two approaches are based on fundamentally independent variables at the first order. The micrometeorological approach is an aerodynamic problem, being a function of $u_{*}$ (turbulence strength) and there is no a priori reason to hypothesize that it shows direct correlation to drivers of biological activity, such as soil temperature. Conversely, the biological correction is based on climatic responses of organisms, and has no physical connection to aerodynamic processes. There is no reason at the present time to suspect that one approach can produce more accurate estimates of NEE than the other. Both approaches carry the potential for high levels of measurement error. However, on theoretical grounds it would seem better to work toward a direct observation of the flux components of $F_{c}$ (the meteorological approach), rather than an indirect proxy (the biological approach). In that spirit, we evaluated the meteorological approach for a 


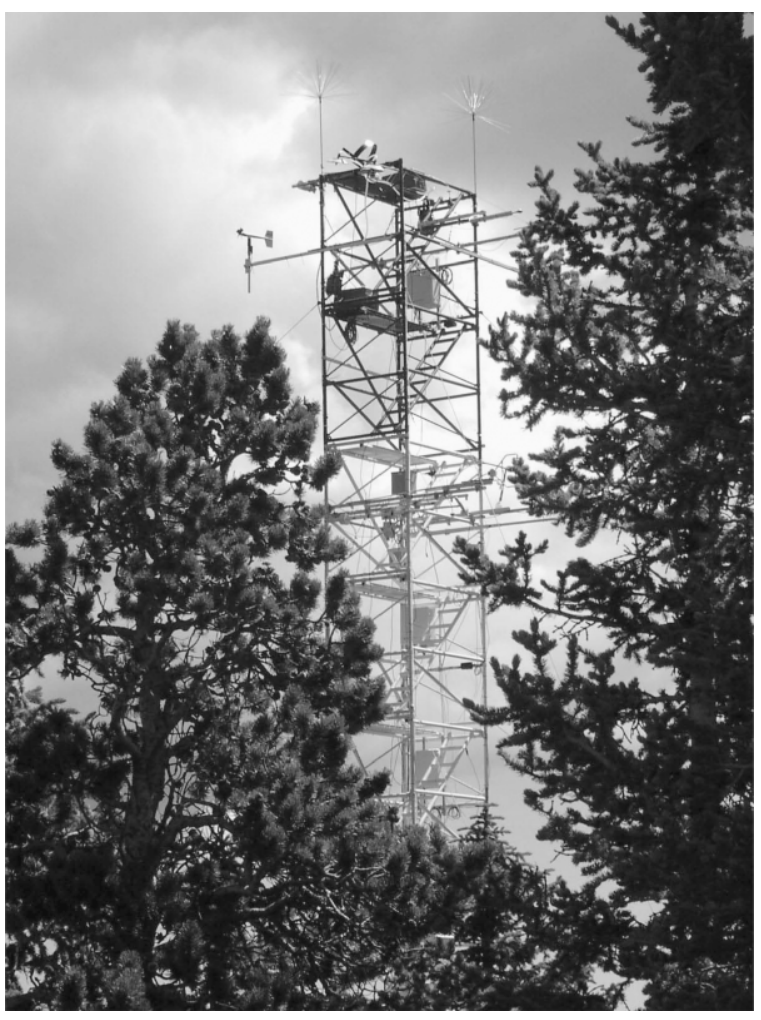

Plate 1. The Niwot Ridge AmeriFlux East Tower surrounded by subalpine forest consisting of lodgepole pine, subalpine fir, and Engelmann spruce, at $3050 \mathrm{~m}$ elevation in the Rocky Mountains, Colorado, USA. Photo credit: J. P. Sparks.

single site where advective fluxes are likely to be high and compare its impact on $F_{c}$ estimates with that from the traditional biological approach. The results of our study demonstrate that the uncertainties in the meteorological approach are currently just as high, if not higher, than those of the biological approach. However, it did provide some useful generalizations for organizing advective fluxes, assessing their sensitivity to assumptions such as similarity, and bracketing the overall uncertainties in the estimate of NEE for this site.

Our analysis showed that use of the biological correction with a $u_{*}$ cut-off point of $0.2 \mathrm{~m} / \mathrm{s}$, caused the six-year cumulative $F_{c}$ to be $48 \%$ lower than the estimates with no correction for periods of high atmospheric stability. The addition of the advective flux terms caused the six-year cumulative $F_{c}$ to be $82 \%$ lower than uncorrected values and $65 \%$ lower than values obtained with the traditional biological approach. Thus, the method used to fill periods of stable atmospheric conditions in the NEE record, at least for this site, has a significant impact on the estimated NEE. When considering shorter time frames (e.g., the monthly time frame) the difference between the two types of corrections is not as great; we estimated the difference to average $10 \%$ at the monthly scale. In any multiple-year analysis, however, differences between estimates using the two types of corrections will accumulate, and in the face of a systematic bias in one type of correction vs. another, large differences in cumulative $F_{c}$ can emerge. In our studies, the biological correction tended to overestimate the rate of $\mathrm{C}$ sequestration, compared to the meteorological correction (Fig. 7). This is because there is a positive $\mathrm{CO}_{2}$ flux due to $F_{\text {hadv }}$ at $u_{*}$ values above 0.2 $\mathrm{m}^{-1}$, which is not balanced by a negative $\mathrm{CO}_{2}$ flux due to $F_{\text {vadv. }}$.

Our past studies have shown that advective fluxes during stable periods are associated with downslope gravitational flows (Yi et al. 2005, Sun et al. 2007). Both $F_{\text {hadv }}$ and $F_{\text {vadv }}$ during the summer growing season were inversely correlated with $u_{*}$ below an upper limit (Fig. 5), indicating that the advective fluxes were of the greatest magnitude and most frequent when turbulent intensity was low, as often occurs during nighttime periods. Nighttime gravitational flows at this site are common during the summer when radiation cooling from the open alpine tundra above the Niwot Ridge site produces dense, cool air that flows downslope under the force of gravity. The nighttime mean horizontal $\left[\mathrm{CO}_{2}\right]$ gradient in the lower canopy space generally ranged from $0.015-0.025 \mathrm{ppm} / \mathrm{m}$ (Fig. 2). The positive sign of the gradient indicates an increase in $\left[\mathrm{CO}_{2}\right]$ along the downslope vector and, in the presence of a downslope drainage flow, causes a positive advective flux $\left(F_{\text {hadv }}\right)$. The vertical advective fluxes that we measured $\left(F_{\text {vadv }}\right)$ are likely also due to downslope drainage flow, though in an indirect manner. The convergence of several drainage channels (both above and beneath the canopy) may be meeting in the vicinity of the tower flux site, possibly causing the mean flow to be forced upward, and resulting in a mean positive vertical velocity (Turnipseed et al. 2004). In the presence of a negative vertical gradient in $\mathrm{CO}_{2}$ concentration ( $\mathrm{CO}_{2}$ concentrations decrease with height), the upward $\bar{w}$ causes $F_{\text {vadv }}$ to be negative in sign. This condition differs from that seen at most forest sites, where nighttime bias in $\bar{w}$ tends to be negative due to atmospheric subsidence, and $F_{\text {vadv }}$ tends to be positive (Aubinet et al. 2005). Advective fluxes were observed during daytime periods, and during the winter, though they tended to be considerably lower than those during nighttime summer periods.

Summertime, nighttime advective $\mathrm{CO}_{2}$ fluxes averaged 2.76 and $-1.46 \mu \mathrm{mol} \cdot \mathrm{m}^{-2} \cdot \mathrm{s}^{-1}$ for $F_{\text {hadv }}$ and $F_{\text {vadv }}$, respectively. These values are less than the summertime, daytime turbulent $\mathrm{CO}_{2}$ fluxes that we have observed (Monson et al. 2002), but similar to summertime, nighttime turbulent fluxes (Monson et al. 2002) and summertime chamber measurements of soil respiration (Scott-Denton et al. 2006). However, the rare, but extreme values we observed for both $F_{\text {hadv }}$ and $F_{\text {vadv }}$ $\left(>30 \mu \mathrm{mol} \cdot \mathrm{m}^{-2} \cdot \mathrm{s}^{-1}\right.$ and $<-20 \mu \mathrm{mol} \cdot \mathrm{m}^{-2} \cdot \mathrm{s}^{-1}$; respectively) were considerably higher than the turbulent $\mathrm{CO}_{2}$ fluxes that we typically measure. These high values cause some suspicion that there are conditions in which our 
experimental design was not able to accurately characterize the advective fluxes. Spatial heterogeneity in soil moisture exists a few hundred meters west of the site, including a perennial bog with potentially high respiration rates. Additionally, past analyses have shown that many of the periods with extremely high mean fluxes are also characterized by high levels of within-canopy directional wind shear $\left(>90^{\circ}\right)$. Depending on how frequently the advective wind moves back and forth across areas with heterogeneous vegetation, the downslope $\left[\mathrm{CO}_{2}\right]$ gradient can potentially loose stationarity, causing complexities in the temporal and spatial distribution of $\mathrm{CO}_{2}$ that cannot be accurately resolved with our sampling scheme. There is clearly room for better understanding the limitations of our experimental design given natural variation in the time and length scales that characterize the wind and $\mathrm{CO}_{2}$ fields at the site, and the relationship of these limitations to the extremely high values we occasionally observed for $F_{\text {hadv }}$ and $F_{\text {vadv }}$.

Using vertical profile measurements with four towers within a relatively limited spatial footprint, we were able to test the assumptions underlying the "similarity approach," one of the commonly used approaches to characterizing horizontal gradients in $\mathrm{CO}_{2}$ and wind speed when spatially distributed measurements are inadequate or missing (e.g., Aubinet et al. 2003, Staebler and Fitzgarrald 2004). At our site, the similarity approach was inadequate for capturing the vertical profile of the horizontal $\mathrm{CO}_{2}$ gradient; it was not sufficient to assume that the vertical profile in this gradient could be transferred spatially within the control volume. The error caused by an assumption of spatial similarity was dependent on $u_{*}$, with the largest errors (on average, $21 \%$ of $F_{\text {hadv }}$ ) occurring at low $u_{*}$, where $F_{\text {hadv }}$ is largest in magnitude. The adequacy of the similarity approach for estimating $F_{\text {hadv }}$ is clearly going to vary from site to site, and we are not able to comment from our analysis on the generality of the approach or whether an error of $21 \%$ is acceptable or not. However, our multiple-tower design does provide a means for assessing the amount of error in the similarity approach when applied to our site, a metric that may be useful to others contemplating use of the approach.

Our results represent the first comprehensive assessment of how advective $\mathrm{CO}_{2}$ fluxes, commonly ignored in the $\mathrm{CO}_{2}$ budgets of tower flux sites, affect multi-year estimates of NEE for a site in complex (mountainous) terrain. Complex terrain can induce atmospheric flows and mean $\mathrm{CO}_{2}$ concentration gradients that are not normally included in local to regional budgets. Native forest ecosystems often occur in hilly or mountainous terrain and it is these ecosystems that often reflect the principal regional carbon sinks and are most in need of accurate accounting during the measurement of NEE. With over 200 global sites reporting continuous data for NEE as part of FLUXNET, and with most sites ignoring uncertainties due to complex terrain, our studies bring to light a problem of potentially large scope. It is likely that many researchers at these various flux sites will continue to use the traditional "biological" correction (based on the NEE vs. soil temperature relationship) as a means of correcting their flux estimates for the effects of stable nighttime periods; the relationship is relatively simple given the requirements for alternative approaches, and it is generally well accepted in the reviewed literature. Our analysis points out that although the traditional approach is convenient, it is not congruent with direct measurements of the component fluxes. The gap between the traditional approach and true micrometeorological measurements will be closed when we better understand observed nighttime $\mathrm{CO}_{2}$ fluxes within the context of local canopy structure, topography, and their effect on air flows within and immediately above the canopy.

\section{ACKNOWLedgMents}

This work was financially supported by grants from the SouthCentral Section of the National Institute for Global Environmental Change (NIGEC; Cooperative Agreement No. DE-FC03-90ER61010), the U.S. Department of Energy (BER; Grant No. DE-FG02-03ER63637), and the U.S. Geological Survey core research and global climate change program. Any opinions, findings, and conclusions or recommendations expressed in this publication are those of the authors and do not necessarily reflect the views of the DOE or USGS. We thank David Fitzjarrald, Jielun Sun, and an anonymous reviewer for their valuable comments on the manuscript. Very valuable contributions to the development and operation of the tower measurement systems were made by Gordon McLean and Tony Delany of the National Center for Atmospheric Research, Boulder. The support of Bill Bowman (Director of the University of Colorado Mountain Research Station, MRS), Steve Seibold (MRS), and Edwin Weeks (USGS) is gratefully acknowledged. We are grateful for permission by the U.S. Forest Service to conduct studies in the Roosevelt National Forest, Colorado.

\section{Literature Cited}

Acevedo, O. C., A. L. L. Moraees, R. Da Silva, D. R. Fitzjarrald, R. K. Sakai, R. M. Staebler, and M. J. Czikowsky. 2004. Inferring nocturnal surface fluxes from vertical profiles of scalars in an Amazon pasture. Global Change Biology 10:886-894.

Aubinet, M., et al. 2005. Comparing $\mathrm{CO}_{2}$ storage and advection conditions at night at different CarboEuro sites. BoundaryLayer Meteorology 116:63-94.

Aubinet, M., B. Heinesch, and M. Yernaux. 2003. Horizontal and vertical $\mathrm{CO}_{2}$ advection in a sloping forest. BoundaryLayer Meteorology 108:397-417.

Baldocchi, D. D. 2003. Assessing ecosystem carbon balance: problems and prospects of the eddy covariance technique. Global Change Biology 9:479-492.

Baldocchi, D. D., E. Falge, and L. Gu, et al. 2001. FLUXNET: a new tool to study the temporal and spatial variability of ecosystem-scale carbon dioxide, water vapor, and energy flux densities. Bulletin of the American Meteorological Society 82:2415-2434

Baldocchi, D. D., J. J. Finnigan, K. W. Wilson, K. T. Paw U, and E. Falge. 2000. On measuring net ecosystem carbon exchange in complex terrain over tall vegetation. BoundaryLayer Meteorology 96:257-291.

Brazel, A., and P. Brazel. 1983. Summer diurnal wind patterns at Niwot Ridge, CO. Physical Geography 4:53-61. 
Feigenwinter, C., C. Bernhofer, and R. Vogt. 2004. The influence of advection on the short term $\mathrm{CO}_{2}$-budget in and above a forest canopy. Boundary-Layer Meteorology 113: 201-204.

Finnigan, J. 1999. A comment on the paper by Lee (1998): "On micrometeorological observations of surface-air exchange over tall vegetation." Agricultural Forest and Meteorology 97:55-64.

Goulden, M. L., J. W. Munger, S. M. Fan, B. C. Daube, and S. C. Wofsy. 1996. Measurements of carbon sequestration by long-term eddy covariance: methods and a critical evaluation of accuracy. Global Change Biology 2:169-182.

Lee, X. H. 1998. On micrometeorological observations of surface-air exchange over tall vegetation. Agricultural and Forest Meteorology 91:39-49.

Lee, X., and X. Hu. 2002. Forest-air fluxes of carbon and energy over non-flat terrain. Boundary-Layer Meteorology 103:277-301.

Marcolla, B., A. Cescatti, L. Montagnani, G. Manca, G. Kerschbaumer, and S. Minerbi. 2005. Importance of advection in the atmospheric $\mathrm{CO}_{2}$ exchanges of an alpine forest. Agricultural and Forest Meteorology 130:193-206.

Massman, W. J., and X. Lee. 2002. Eddy covariance flux corrections and uncertainties in long-term studies of carbon and energy exchanges. Agricultural and Forest Meteorology 113:121-144.

Monson, R. K., A. A. Turnipseed, J. P. Sparks, P. C. Harley, L. E. Scott-Denton, K. L. Sparks, and T. E. Huxman. 2002 Carbon sequestration in a high-elevation, subalpine forest. Global Change Biology 8:459-478.

Paw U, K. T., D. D. Baldocchi, T. P. Meyers, and K. B. Wilson. 2000. Correction of eddy covariance measurements incorporating both advective effects and density fluxes. Boundary Layer Meteorology 97:487-511.

Schimel, D. S., T. G. F. Kittel, S. Running, R. K. Monson, A. A. Turnipseed, and D. Anderson. 2002. Carbon sequestration studied in Western U.S. mountains. EOS Transactions AGU 83:445, 449.

Scott-Denton, L. E., T. N. Rosenstiel, and R. K. Monson. 2006. Differential controls by climate and substrate over the heterotrophic and rhizospheric components of soil respiration. Global Change Biology 12:205-216.
Staebler, R. M., and D. R. Fitzjarrald. 2004. Observing subcanopy $\mathrm{CO}_{2}$ advection. Agricultural and Forest Meteorology 122:139-156.

Staebler, R. M., and D. R. Fitzjarrald. 2005. Measuring canopy structure and kinematics of subcanopy flows in two forests. Journal of Applied Meteorology 44:1161-1179.

Sun, J., S. P. Burns, A. C. Delany, S. P. Oncley, A. A Turnipseed, B. B. Stephens, D. H. Lenschow, M. A. LeMone, R. K. Monson, and D. E. Anderson. 2007. $\mathrm{CO}_{2}$ transport over complex terrain. Agricultural and Forest Meteorology 145:1-21.

Turnipseed, A. A., D. E. Anderson, P. D. Blanken, W. M. Baugh, and R. K. Monson. 2003. Airflows and turbulent flux measurements in mountainous terrain. Part 1. Canopy and local effects. Agricultural and Forest Meteorology 119:1-21.

Turnipseed, A. A., D. E. Anderson, P. D. Blanken, and R. K. Monson. 2002. Energy balance above a high-elevation subalpine forest in complex topography. Agricultural and Forest Meteorology 110:177-201.

Turnipseed, A. A., D. E. Anderson, S. Burns, P. D. Blanken, and R. K. Monson. 2004. Airflows and turbulent flux measurements in mountainous terrain. Part 2. Mesoscale effects. Agricultural and Forest Meteorology 125:187-205.

Wang, W., K. J. Davis, B. D. Cook, P. Bakwin, C. Yi, D. Ricciuto, and M. Butler. 2005. Surface layer $\mathrm{CO}_{2}$ budget and advective contributions to measurements of net ecosystem-atmosphere exchange of $\mathrm{CO}_{2}$. Agricultural and Forest Meteorology 135:202-214.

Wilczak, J. M., S. P. Oncley, and S. A. Stage. 2001. Sonic anemometer tilt correction algorithm. Boundary-Layer Meteorology 99:127-150

Yi, C., K. J. Davis, P. S. Bakwin, B. W. Berger, and L. Marr. 2000. The influence of advection on measurements of the net ecosystem-atmosphere exchange of $\mathrm{CO}_{2}$ from a very tall tower. Journal of Geophysical Research 105:9991-9999.

Yi, C., R. K. Monson, Z. Zhai, D. E. Anderson, B. Lamb, G. Allwine, A. A. Turnipseed, and S. P. Burns. 2005. Modeling and measuring the nocturnal drainage flow in a high-elevation, subalpine forest with complex terrain. Journal of Geophysical Research 110:D22303. [doi: 10.1029/ 2005JD006282]

\section{APPENDIX}

Comparison of horizontal advection calculated by the cosine-referenced technique and consideration of two-dimensional wind flows (Ecological Archives A018-049-A1). 